\title{
Asymmetric Threshold Linkages of Inter-Sector Activity in International Equity Markets
}

\author{
Eun S. Ahn (Correspondent author) \\ University of Hawaii - West Oahu \\ 96-129 Ala 'Ike, Pearl City, HI 96782, USA \\ Tel: 1-808-454-4846 E-mail: euna@hawaii.edu
}

\author{
Jin Man Lee \\ DePaul University \\ 1 E Jackson Blvd, Chicago, IL 60559, USA \\ Tel: 1-312-362-5970 E-mail: jlee141@depaul.edu
}

Received: August 2, 2010

Accepted: August 31, 2010

doi:10.5539/ijef.v3n2p52

\begin{abstract}
The inter-sector study shows index performance on a sector-by-sector basis was heavily impacted by the country which closed just prior to its own market's open as we expect from the broad index. This study also found the influence of a country's lagged price movements on its own market varied from one country to another and from sector-to-sector. The investigation into industry specific indexes by applying the Multivariate Adaptive Regression Spline (MARS) model allowed us to untangle the data and capture the asymmetric dynamics in international financial markets. The sector specific study results revealed the strong linkages when markets were excessively volatile and also identified the difference between the impact of positive and negative extreme price movements.
\end{abstract}

Keywords: Stock Market Indexes, International Transmission, Nonlinear Time Series, Multivariate Adaptive Regression Spline (MARS), Asymmetric Information

\section{Introduction}

The study of interdependence between international stock index returns has been an interesting topic as financial markets integrates. Individual investors, corporate portfolio managers, as well as academics are interested in discovering more information on this topic. Evidence from these studies may have major implications on international asset pricing models as well as unravel the extent to which a country's asset risk may or may not be internationally diversifiable.

Grubel (1968) was one of the pioneers in this area of study as he applied the Markowitz-Tobin model on 11 industrialized countries for the time period 1959-1966. His research showed on a risk-return basis that an internationally diversified stock portfolio investment would be advantageous over a non-internationally diversified stock index. Additional studies shortly followed which helped confirm the lack of correlation in performance among international stock indexes and hence the benefits of diversification (Grubel and Fadner (1971), Lessard (1974), Solnik (1974), Panton, Lessig, and Joy (1976), and Hilliard (1979)).

Many studies have come to suspect markets might be more integrated due to recent liberalization of the international equity markets. Studies have surfaced which showed evidence of comovement in international stock indexes. Jaffe and Westerfield (1985) studied five countries using daily closing prices. Their results generally revealed a significant and positive correlation between the U.S. and other international equity returns. Eun and Shim (1989) conducted a similar study utilizing daily data and also found synchronous price movement between the international equity markets. More recently, Cheung, He, and Ng (1997) applied a multivariate method using region-specific instrumental variables to predict international stock market performance for national stock markets in Europe, North America, and Asia. Their study showed similar instruments of one region can help predict equity returns of another which support the evidence of price transmission among regional stock markets. In particular, this study found the North American region to be the most influential. Ehrmann et al (2005) applied a multifactor model to observe financial market shocks and their transmission between the U.S. and the euro zone for the time period 1989-2004. 
Their study showed international transmission of shocks exists both within asset classes as well as across markets. The study also revealed the U.S. dominance in global financial market influence.

A previous study conducted by Becker, Finnerty, and Gupta (1990) also reported similar conclusions. Their study showed price movements in the U.S. stock market greatly impacted the next day performance of the Japanese stock market; however, the Japanese equity market only had a small influence on the U.S. market. Previous studies conducted by Odier and Solnik (1993), Lin, Engle, and Ito (1994), and Campbell, Koedijk, and Kofman (2002) also showed evidence that markets are correlated at the international level and especially vulnerable to U.S. market declines. Our finding supports their work but also helps explain the unilateral relationship in the influence (only U.S. to Japan) between the two countries.

As an extension of previous studies, this paper explores the extent of interdependence of international stock indexes at the general, broad-based level, as well as the inter-sector level. Another extension of the literatim is that although shocks may be country specific, more information can be gained by investigating the price influence from one country to another on a sector-by-sector basis. The main idea on the sector based linkage in the international finance market is that certain industries are more impacted by domestic factors while other industries may be more influenced by external factors. A country's healthcare and utilities sectors are more likely to be linked to its own domestic markets rather than international markets, while the energy and technology sectors are more influenced by international markets. For most countries, the healthcare and utilities industries are typically heavily influenced by domestic factors while energy and technology industries tend to have external factors affect them to a greater extent. Clarkson et al (2002) showed as an industry's revenue from international activities increased, the more it is influenced by international factors. Therefore, we will investigate the strength of the interdependence among international stock markets by focusing on industry specific returns.

Furthermore, our study investigates the threshold effects on international financial linkage. The notion of threshold influence comes from the idea that bad news and good news impact markets differently. J. Bialkowski et al (2006) tested for asymmetries in financial markets using a bivariate Markov switching framework for U.S., Japan, UK, and Germany during 1984-2003 and discovered transmission of returns were stronger during times of crisis. Dungey and Martin (2007) utilized a dynamic latent factor framework to examine the link between equity and currency markets during the East Asian financial crisis of 1997-98. They found both cross-market and cross-border influences were statistically significant during periods of crisis. H. Kim et al (2009) used a modified nonlinear unit root test (inf - $t$ test) to investigate the existence of nonlinear cointegration between G7 stock indexes for the time period 1969-2007. Their research revealed strong evidence of nonlinear comovement between stock indexes in France, Germany, Italy, UK, and the U.S. stock market. Evans and McMillan (2009) studied asymmetric return patterns for 33 international stock market indexes during 1990-2005 and found evidence of asymmetric behavior in returns across all the markets. To confirm the findings of previous studies as well as our own, we conducted an asymmetric/threshold analysis utilizing the multivariate adaptive regressive spline (MARS) model.

The rest of this paper is organized as follows. In the following section, we describe the ICAPM model. In Section 3, the VAR and MARS models are explained. The empirical results of our study are presented in Section 4. Section 5 summarizes and concludes our findings.

\section{International asset pricing model}

International Capital Asset Pricing Model (ICAPM) shows that the expected return on any asset is a function of the conditional sensitivity between its return and the return on a number of hedging portfolios. According to this model, a country's investment risk may be measured as the covariance of the return of investing in a specific country against the returns of a world stock portfolio. Therefore, the benefits of investing in an internationally diversified portfolio should move inversely with the degree of this covariance. Similar models were utilized by DeSantis and Gerard (1997), Chan, Karolyi and Stulz (1992).

$$
E\left[r_{i, t+1} \mid \Phi_{t}\right]=r_{f, t+1}+\frac{\operatorname{Cov}\left[r_{i, t+1}, r_{m, t+1} \mid \Phi_{t}\right]}{\operatorname{Var}\left[r_{m, t+1} \mid \Phi_{t}\right]} E\left[r_{m, t+1}-r_{f, t+1} \mid \Phi_{t}\right]
$$

where, $\Phi_{\mathrm{t}}=$ market information set available to investors at end of time $\mathrm{t}$

$r_{i, t+l}$ is the return on asset $\mathrm{i}$

$r_{f, t+l}$ is the rate of return on the risk free asset

$r_{m, t+1}$ is the return on the world market portfolio

$E\left[\mathrm{r}_{\mathrm{m}, \mathrm{t}+1^{-}} \mathrm{r}_{\mathrm{f}, \mathrm{t}+1} \mid \Phi_{\mathrm{t}}\right]$ is the expected excess return to the world market portfolio 
The equation can be express by

$$
\begin{gathered}
E\left[r_{i, t+1} \mid \Phi_{t}\right]=r_{f, t-1}+\beta_{i, t+1} E\left[r_{m, t+1}-r_{f, t+1} \mid \Phi_{t}\right] \\
\text { where } \beta_{i, t+1}=\frac{\operatorname{Cov}\left[r_{i, t+1}, r_{m, t+1} \mid \Phi_{t}\right]}{\operatorname{Var}\left[r_{m, t+1} \mid \Phi_{t}\right]} .
\end{gathered}
$$

As shown in equation (2) above, the expected return of country $i$ can be expressed by the risk free return and excessive market return from a world portfolio. From a long-run horizon perspective, the market return $\left(r_{m, t+1}\right)$ can be expected to be stable over time. $\beta_{i, t+l}$ represents the systematic risk for county $i$ with respect to world return. If county $i$ has low $\beta_{i, t+1}$, then the market tends to be less integrated with the world market while higher $\beta_{i, t+1}$ can be interpreted as the market being proactive to the changes of world market returns.

From equation (2), we can extend the short-run expected return in county $i$. As the time interval decreases (as in the case of daily stock market returns), the market return needs to be adjusted by utilizing newly available information. Based on this notion, we can consider the return from previous closing market as well as its own lagged return. Thus, we can build a realized return model as follows:

$$
E\left[r_{i, t} \mid \Phi_{t-1}\right]=r_{f, t-1}+\gamma_{i} E\left[r_{m, t-1}-r_{f, t-1} \mid \Phi_{t-1}\right]+\delta_{i} E\left[r_{i, t-1}-r_{f, t-1} \mid \Phi_{t-1}\right],
$$

where $r_{m, t-1}-r_{f, t-1}$ is the excess return of the world market in previous period or previous closing, $r_{i, t-1}-r_{f, t-1}$ is the excessive previous period return of country $\mathrm{i}$.

Now the capital return in country $i$ can be seen as realized by past excessive return from the world market $\left(r_{m, t-1}-r_{f, t-1}\right)$ and domestic market $\left(r_{i, t-1}-r_{f, t-1}\right)$. Please note the original ICAPM model did not consider the local and world effects on a country's return; however, equation (3) considers both world and domestic models. ICAPM assumes the entire world operates under same risk structure (Harvey 1991). Another point to consider is the possibility that shocks (negative or positive) in any one country may have a greater impact on other countries. This may lead to inaccurate portfolio conclusions and unreliable claims regarding the benefits of holding an internationally diversified portfolio.

The world market return can be estimated by the lag or previously closing market return and the domestic return can be estimated by the lag of domestic markets. Based on this dynamic inter-relationship, the utilization of vector autoregressive (VAR) type models would appear suitable to estimate the influence of the market interactions. However, VAR model assumes linearity regardless of the type of shock and size of shocks, such as positive and negative or excessive positive and excessive negative shocks. To find the effects of extreme shocks, we need to apply threshold type of models which are more ideal for explaining such circumstances. In our study, we will adopt the multivariate adaptive regressive spline (MARS) model.

\section{Econometric models}

\subsection{Vector autoregressive model (VAR) on international asset pricing models}

VAR methodology does not assume any structural dependence between the variables, so it is not necessary to rely on any identification restrictions. Structural VARs impose an economic model on the contemporaneous movements of the variables. The most basic form of a VAR treats all variables symmetrically without making reference to the issue of dependence versus independence.

Prior to estimating the VAR models, the data series was checked for stationarity using the augmented Dickey-Fuller and Phillips-Perron unit root tests. Once stationarity was assured with the data series, AIC and SBC tests were conducted to determine the appropriate lag lengths for the final VAR model. To analyze the daily data in our study, we arranged the setup in the following manner:

$$
\begin{aligned}
& J P_{t}=b_{0}+\sum_{i}^{p} b_{1 i} U S_{t-i}+\sum_{i}^{p} b_{2 i} J P_{t-i}+\sum_{i}^{p} b_{3 i} F R_{t-i}+\sum_{i}^{p} b_{4 i} U K_{t-i}+\sum_{i}^{p} b_{5 i} C A_{t-i}+e_{t} \\
& U K_{t}=b_{0}+\sum_{i}^{p} b_{1 i} U S_{t-i}+\sum_{i}^{p} b_{2 i} J P_{t-i+1}+\sum_{i}^{p} b_{3 i} F R_{t-i}+\sum_{i}^{p} b_{4 i} U K_{t-i}+\sum_{i}^{p} b_{5 i} C A_{t-i}+e_{t} \\
& F R_{t}=b_{0}+\sum_{i}^{p} b_{1 i} U S_{t-i}+\sum_{i}^{p} b_{2 i} J P_{t-i+1}+\sum_{i}^{p} b_{3 i} F R_{t-i}+\sum_{i}^{p} b_{4 i} U K_{t-i}+\sum_{i}^{p} b_{5 i} C A_{t-i}+e_{t}
\end{aligned}
$$




$$
\begin{gathered}
C A_{t}=b_{0}+\sum_{i}^{p} b_{1 i} U S_{t-i}+\sum_{i}^{p} b_{2 i} J P_{t-i+1}+\sum_{i}^{p} b_{3 i} F R_{t-i+1}+\sum_{i}^{p} b_{4 i} U K_{t-i+1}+\sum_{i}^{p} b_{5 i} C A_{t-i}+e_{t} \\
U S_{t}=b_{0}+\sum_{i}^{p} b_{1 i} U S_{t-i}+\sum_{i}^{p} b_{2 i} J P_{t-i+1}+\sum_{i}^{p} b_{3 i} F R_{t-i+1}+\sum_{i}^{p} b_{4 i} U K_{t-i+1}+\sum_{i}^{p} b_{5 i} C A_{t-i}+e_{t}
\end{gathered}
$$

As the models above indicate, the Japanese market opens first, and is influenced by previous days' closing markets. However, the UK market will have the same day subscript $(\mathrm{t})$ as the Japanese market but the rest of countries' previous day subscript (t-1). Finally, the U.S. market will be influenced by the same day closing of Japan, UK, and France.

\subsection{Multivariate adaptive regression spline (MARS))}

The MARS approach allows the researcher to specify models in which the coefficients differ by level. This procedure provides complex nonlinear interaction terms to be specified. The MARS approach can fit models in situations where there are distinct breaks in the model (i.e. change in the underlying probability density function of the coefficient and/or complex variable interactions). The advantage of MARS model is the flexibility in different threshold levels. OLS is a special case in MARS. Stokes $(2003,2009)$ summarizes the main idea about MARS as follows.

Multivariate Adaptive Regression Spline (MARS) is a new methodology, attributable to Jerome Friedman, for nonlinear regression modeling. MARS can be conceptualized as a generalization of recursive partitioning that uses spline fitting in lieu of other simple fitting functions. Given a set of predictor variables, MARS fits a model in the form of an expansion in project spline basis functions of predictors chosen during a forward and backward recursive partitioning strategy. MARS produces continuous models for high-dimensional data that can have multiple partitions and predictor variable interactions. Predictor variable contributions and interactions in a MARS model may be analyzed using an ANOVA style decomposition. By letting the predictor variables in MARS be lagged values of a time series, one obtains a new method for nonlinear autoregressive threshold modeling of time series.

MARS builds models of the form

$$
\hat{f}(x)=\sum_{i=1}^{s} c_{i} M_{i}(x),
$$

The model is a weighted sum of basis function where $c_{i}$ is a constant coefficient.

In terms of the MARS notation, this is written as

$$
y=a^{\prime}+c_{1}\left(x-\tau^{*}\right)_{+}-c_{2}\left(\tau^{*}-x\right)_{+}+e
$$

This implies that

$$
\begin{array}{ll}
y=a^{\prime}+c_{1} x+e & \text { for } x>\tau^{*} \\
y=a^{\prime}+c_{2} x+e & \text { for } x<\tau^{*} .
\end{array}
$$

As (6) shows, the $\tau^{*}$ is a threshold value, and ( )+ requires right truncated spline functions that take positive numbers. Thus (6) allows threshold regression model when there is a known threshold point. MARS model allows for more than one threshold value $\left(\tau^{*}\right)$.

MARS starts by repeatedly adding basis function in pairs to the model by forward pass and is estimated by backward pass using Modified form of the Generalized Cross Validation (MGCV) to confirm the best possible model.

$$
M G C V=\left[(1 / N) \sum_{i=1}^{N}\left(y_{i}-\hat{f}(X)\right)^{2}\right] /\left[1-\left[C(M)^{*} / N\right]^{2}\right],
$$

where there are $N$ observations, and $C(M)$ is a complexity penalty. The default is set equal to a function of the effective number of parameters. The formula used is

$$
C(M)^{*}=C(M)+\delta M
$$

A significant feature of this extension of MARS is its ability to produce models with limit cycles when modeling time series data that exhibit periodic behavior. In a physical context, limit cycles represent a stationary state of sustained oscillations, a satisfying behavior for any model of a time series with periodic behavior. The theory of MARS modeling has been adapted from papers by Friedman (1991) and Lewis and Stevens (1991). 


\section{Empirical Evidence}

\subsection{VAR results and findings from broad-based study}

We used Morgan Stanley Capital International Perspective from January of 1996 to December of 2006 for Japan, UK, France, Canada and U.S. daily return data. We include broad index and four industry specific indexes; energy, technology, utility, healthcare. AIC and SBC tests show that mixed results with one or two lags, so we use two lags to be consistent with all markets.

Our investigation into synchronous performance for broad-based stock indexes across countries (Japan, UK, France, U.S., Canada) using VAR models revealed trading in any country's stock index was significantly influenced by the previous daily returns of the country which ceased trading just prior to its own market's open. (Note1)

Our study showed markets in Asia (Japan) significantly influenced Europe (UK and France), Europe significantly influenced North America (U.S. and Canada), and North America significantly influenced Japan. (Note 2) VAR model showed Japan's daily return $\left(\mathrm{NK}_{\mathrm{JP}, t}\right)$ strongly impacted the markets in France $\left(\mathrm{SB}_{\mathrm{FR}, \mathrm{t}}\right)$ and $\mathrm{UK}\left(\mathrm{MB}_{\mathrm{UK}}, \mathrm{t}\right)$, respectively. The Canadian stock market index $\left(\mathrm{TX}_{\mathrm{CA}, \mathrm{t}}\right)$ revealed France $\left(\mathrm{SB}_{\mathrm{FR}, \mathrm{t}}\right)$ and $\mathrm{UK}\left(\mathrm{MB}_{\mathrm{UK}, \mathrm{t}}\right)$ as statistically significant. In the U.S., results revealed the daily rate of return for France $\left(\mathrm{SB}_{\mathrm{FR}, t}\right)$ and $\mathrm{UK}\left(\mathrm{MB}_{\mathrm{UK}}, \mathrm{t}\right)$ highly influenced the current performance of U.S. broad-based stock index $\left(\mathrm{SP}_{\mathrm{U} . \mathrm{S} ., \mathrm{t}}\right)$. Finally, Japan's stock market index daily returns $\left(\mathrm{NK}_{\mathrm{JP}, \mathrm{t}}\right)$ were significantly influenced by the U.S. market's performance $\left(\mathrm{SP}_{\mathrm{U} . \mathrm{S} ., \mathrm{t}-1}\right)$. (See Table I)

The lag of a country's own index has relatively weaker influence when compared to the change of the market index for the country which just previously closed. For example, the coefficient of the U.S. market on Japan's Nikkei index return shows 0.34 while its own effect shows -0.10 . This is also true for all markets. (See Table 1) Our evidence would suggest a model which only utilizes its own market's lagged returns is neglecting available information which is more current and relevant.

Prior research conducted by Becker, Finnerty, and Gupta (1990) and Ishii (2008) showed movement in the North American (U.S.) market influenced Asia (Japan) but the reverse impact was weak. Our finding supports their work but also explains the unilateral relationship in the influence (only U.S. to Japan) between the two countries. The results show the U.S. equity market strongly impacts Japan's since the U.S. stock index market is the most recent one to close prior to Japan's open. However, Japan's market does not significantly influence the U.S. market because it is not the last market to cease trading before the U.S. market commences. We confirm that the European market's daily return is what influences the U.S. market. This is due to the fact that the European market is the last to stop trading, not Japan's, before the trading session begins in the U.S.

Our study supports the existence of strong integration in international financial markets. The evidence of highly integrated markets reflects the importance of the impact other market's open and close price movement have over one's own country's specific influence. Our broad-based study results led us into investigating this relationship at the sector specific level to help substantiate our findings. If we observed similar results in the sector-based index study, it would help confirm the existence of financial integration in international markets. However, if this was not the case, we would identify stylized facts at the individual level of each sector by country.

\subsection{VAR results and findings from industry specific indexes}

The sector-by-sector basis analysis allowed us to observe the strength of the integration of markets by industry. In addition, an investigation into industry specific performance allowed us to see if the relationship at the broad-based level also held true on a sector-by-sector basis. The sector analysis also provided us with information on which industries were more influenced by internal (domestic) or external (international) factors.

The VAR results from the inter-sector results show that index performance even on a sector-by-sector basis was heavily impacted by the country which closed just prior to its own market's open regardless of country and sector. These results confirmed the strong integration of international market in sector based indexes.

The influence of a country's lagged price movements on its own market varied from one country to another and from sector-to-sector. In the utilities sector, one's own lagged daily returns significantly influenced its own market with the exception of France and UK. The results for the technology industry displayed only the U.S. as the sole country where its own lagged performance significantly impacted its market. As for heathcare, all the countries showed its own previous price movement significantly influenced the following trading period. In energies, with the exception of Japan and Canada, all other countries showed one's lagged price effect significantly impacted its own price movement. (See Table 2)

External shock influence varied depending upon industry and country. For Canada, the technology sector $\left(\mathrm{TE}_{\mathrm{CA}, \mathrm{t}}\right)$ was the most influenced by external shocks (price movements in other countries), while the healthcare sector $\left(\mathrm{HC}_{\mathrm{CA}}\right.$, 
t) was the most influenced by domestic shocks. The U.S. markets were significantly influenced by domestic shocks in all the sectors in our study. The UK showed significant external shock transmission in utility $\left(\mathrm{UT}_{\mathrm{UK}, t}\right)$ and technology $\left(\mathrm{TE}_{\mathrm{UK}, \mathrm{t}}\right)$ stock indexes while displaying significant internal shock influence for the energy and healthcare industries. France displayed strong internal shock transmission from healthcare $\left(\mathrm{HC}_{\mathrm{FR}, \mathrm{t}}\right)$ and energy $\left(\mathrm{EN}_{\mathrm{FR}, \mathrm{t}}\right)$ sectors while technology $\left(\mathrm{TE}_{\mathrm{FR}, \mathrm{t}}\right)$ and utility $\left(\mathrm{UT}_{\mathrm{FR}, \mathrm{t}}\right)$ sectors revealed significant external influence. Japan's results revealed strong internal shock transmission of prices for healthcare $\left(\mathrm{HC}_{\mathrm{JP}, \mathrm{t}}\right)$ and utility $\left(\mathrm{UT}_{\mathrm{JP}, \mathrm{t}}\right)$ while the technology $\left(\mathrm{TE}_{\mathrm{JP}, \mathrm{t}}\right)$ and energy $\left(\mathrm{EN}_{\mathrm{JP}, \mathrm{t}}\right)$ sectors showed significant external influence. In addition, for Japan, the U.S. price movements displayed significant influence for all sectors. (See Table 2)

Typically, it would appear the healthcare stock index was most significantly influenced by its own lagged daily returns and the energy sector also showed signs of being significant for a majority of the countries (Canada and Japan as exceptions). The technology sector, with the exception of the U.S., was clearly the least influenced by its own country's lagged price movements. As for utilities, UK and France showed their markets were more dependent on the price movement of other markets. The inter-sector analysis helped track which variable(s) may be most influencing on a certain country and/or industry.

The VAR model assumes all significant variables have the same impact regardless of the size of the shock. However, it is a well known fact that threshold effects exist in financial markets (J. Bialkowski et al (2006), Dungey and Martin (2007), H. Kim et al (2009), Evans and McMillan (2009). To confirm the findings of previous studies as well as our own VAR study results, we conducted an asymmetric/threshold analysis utilizing the multivariate adaptive regressive spline (MARS) model.

\subsection{MARS results for broad-based indexes}

Tables 3 summarizes the dynamic relationship of the significant variables ranked in order of importance (importance index $=100$ signals most important variable). The broad-based industry index displayed similar results as our VAR study. Although there appears to be some interaction between France and Japan's market, the overall flow theme is fairly consistent with the VAR results - the previous closing markets influence the following market's trading session. Asia $\rightarrow$ Europe $\rightarrow$ N. America. (See Figure 1)

\subsection{MARS results for industry-specific indexes}

The sector specific results for MARS were also very similar with the VAR study, with the exception of Japan. Just as the VAR results showed for the Canadian market, the MARS model also displayed the technology sector being most influenced by other countries while healthcare was significantly influenced by domestic factors. The MARS results for the U.S. once again showed domestic shocks were significant for all the sectors. The European markets also showed similar result for MARS with the UK displaying significant external shock transmission in utility and technology indexes while displaying significant internal shock influence for the energy and healthcare industries. France displayed strong internal shock transmission for healthcare and energy sectors while technology and utility sectors revealed significant external influence. Japan's results for MARS revealed strong internal shock transmission of prices for healthcare and utility which was also true for VAR. As for the technology and energy sectors in Japan, MARS showed both markets were significantly influenced by external and internal shocks while VAR only revealed external influence in these two markets. However, MARS results did indicate external factors were more important (importance index $=100$ ) in both sectors. (See Table 3 and Figure 2)

It would appear the healthcare stock index was significantly influenced by its own lagged daily returns and the U.S. healthcare price movements for all countries with one exception (Canada not showing significant dependence on U.S. performance.) For technology, one's own market influence was very weak for all countries with the exception of the U.S. Also, the U.S. technology sector was very influential across all other countries technology stock indexes. The energy industry displayed significant internal as well as external factors for all countries in our study with external shocks showing slightly more influence as indicated by the importance index ranking. As for utilities, the U.S., France, and Japan showed their markets were more influenced by internal shocks while Canada and the UK results revealed price movement of other markets impacted their markets to a greater degree.

Overall, even broken down by sector, one can conclude that the trading sessions are clearly significantly influenced by the market which closed just prior to its own open. The flow charts in Figure 2 which display the transmission of prices on a sector-by-sector basis show the general theme as Asia $\rightarrow$ Europe $\rightarrow \mathrm{N}$. America (with the exception of utilities) which is consistent with the MARS broad-based results as well as the VAR results.

\subsection{Asymmetric linkages in international financial market}

The MARS model was able to provide valuable additional information. The nonlinear aspect of the MARS model allowed us to capture the periodic behavior of international financial markets and the asymmetric nature of their relationship to one another. The MARS results displayed the vulnerability of the international equity market to 
extreme daily price movement of the market which closed just prior to its own market's open. Consistently, the coefficients from the MARS model were comparable, if not noticeably larger, than the coefficients for the VAR model. In particular, the MARS model coefficients were many times greater than the VAR model coefficients when threshold levels were exceeded. These results substantiate the asymmetric nature and the vulnerability of the international financial markets to one another's shocks.

By observing Table 3, we can revisit and summarize the asymmetric relationship among international financial markets. The threshold values were identified by MARS using the Modified form of the Generalized Cross Validation (MGCV). The marginal effects can be interpreted as the percent change impact on the target country's equivalent market's daily return given a one percent change in the equivalent market's daily return from the country where the shock originated.

As evident from the results, asymmetric analysis for the broad-based and sector specific market indexes helped confirm our VAR study results. In general, most of the stock indexes were heavily influenced by shocks in the market which closed just prior to its own open. Below are some of the findings from the asymmetric aspects of the linkage.

First, at the broad-based level, threshold behavior was very evident, in particular, the transmission of negative shocks from the previous closing market to the market which traded immediately following. For example, the Japanese market was particularly vulnerable to the U.S. price movement following a weak U.S. closing. As reflected in Table 3, whenever the U.S. market experienced a negative daily return of less than $-0.27 \%$, it transmitted over as a $0.54 \%$ daily change in the Japanese market while a U.S. daily market movement of greater than $-0.27 \%$ impacted the Japan's following daily market performance by $0.29 \%$. Similar results were evident in other markets as well. The Japanese market influenced the UK and France, and the UK and France markets influenced the U.S. and Canada. However, the impact varied depending on the direction and magnitude of the price movement. In summary, the price movement of markets which closed just prior to another's open generally influenced the trading of the following market. The degree of price transmission varied based on the size and sign of the shock as well as the country of origin. Typically, negative shocks had stronger influence relative to positive shocks.

Second, the U.S. market influence dominated the threshold study results at the industry specific level. In particular, all the countries in our study were greatly influenced by the US market shocks in the technology sector. We also confirmed that negative U.S. shocks have greater impacts. There were numerous cases where we can identify the higher impacts of negative shocks compared to positive shocks. For example, for the utility index, whenever the excessive negative U.S. daily returns were lower than $-1.44 \%$, the UK daily market return were impacted by $0.33 \%$ of the shock compared to zero influence when shocks were greater than $-1.44 \%$. The U.S. healthcare index is another good example. Here, Japan's market was influenced by $.32 \%$ whenever the U.S. market experiences an excessive negative return (daily performance falls below $-1.61 \%$ ) while only a $0.12 \%$ shock was transmitted at other times. The MARS model estimates a new linear relationship within the threshold zone which is expressed through a change in the slope once the threshold level is reached. See graphically illustrated example of the U.S. healthcare on Japan's healthcare market on Figure 3.

Third, we also observed that extreme positive shocks in the U.S. resulted in a large positive impact on the European energy markets (UK and France) while an extreme positive shock from the UK had a strong negative influence on the Japanese utility market. Typically, extreme shocks in the U.S. and/or Canada greatly influenced the Japanese and UK markets while the UK and/or France impacted the U.S. market. For the technology index, an extreme positive shock (more than $5.29 \%$ daily return) from the U.S. had a strong impact on the Japanese market and similar influence from the UK to the U.S. when the UK market jumped higher than $7.25 \%$ on a daily basis. See Figure 4 for graphically illustration. Notice the marginal effects move from 0.12 to 0.41 when the $7.25 \%$ threshold is reached. Finally, the excessive positive shock influences were identified in the following markets: U.S. to France in the utility index; Canada to Japan and U.S. to UK and France in the energy index.

Finally, based on the second and third findings described above, it is obvious asymmetric behavior is an important dimension to understanding international financial market linkages. The investigation into industry specific indexes by applying the MARS model allowed us to untangle the data and capture the asymmetric dynamics in international financial markets. The sector specific study results revealed the strong linkages when markets were excessively volatile and also identified the difference between the impact of positive and negative extreme price movements. This ability was especially evident when observing the greater impact of excessive negative shocks in the following markets: UK to U.S. and France to U.S. in the utility index; Japan to UK, U.S. to Canada, and France to Canada and U.S. for the technology index; U.S. to Japan, UK, and France and UK to U.S. in the healthcare index; Canada to UK and France and UK to Canada and U.S. in the energy index. 


\section{Summary}

In our research, we investigated the integration and transmission of daily stock market returns for five countries (Japan, UK, France, U.S., and Canada). We applied the VAR and MARS models to study this relationship at the broad-based as well as industry specific levels. Our research revealed that the trading sessions were significantly influenced by the market which closed just prior to its own open. Our findings revealed, typically, the previous market's price movement had even a stronger influence than one's own market's lagged data. This is most likely due to the fact that one's own lagged price movements neglected to capture more current information which was included in the previous market's trading session. The results were consistent for the broad-based and sector specific indexes as well as the VAR and MARS models.

Although the broad-based results for both the VAR and MARS models were robust, we also investigated the relationship on a sector-by-sector basis to observe the strength of the integration of markets by industry. The inter-sector analysis helped track which variable(s) may be most influencing a certain country and/or industry. The industry specific analysis allowed us to see which industries were more influenced by internal (domestic) or external (international) factors. Our findings showed the degree of influence of a country's lagged price movements on its own market (internal factors) as well as the influence of other markets (external factors) varied by country as well as sectors. However, in general, for all countries both the VAR and MARS studies revealed the healthcare sector to be more influenced by internal shocks while technology was heavily impacted by external shocks. As for utilities and energy, it varied slightly depending on the country as well as the model.

The results from our study displayed evidence of asymmetric influence from the previous market from both extreme positive and negative price movements. The nonlinear aspect of the MARS model was able to provide valuable additional detailed information with its unique ability to capture and highlight the asymmetric nature of international financial markets. The MARS results displayed the vulnerability of the international equity markets to extreme daily price movements (especially, excessive negative shocks) of the markets which closed just prior to its own market's open. The MARS results revealed that at the broad-based level, threshold behavior was very evident in the transmission of negative shocks from the previous closing market to the market which traded immediately following. The U.S. market influence dominated the threshold study results at the industry specific level. We also observed that extreme positive shocks in the U.S. resulted in a large positive impact on the European energy markets (UK and France) while an extreme positive shock from the UK had a strong negative influence on the Japanese utility market.

Finally, based on the findings described above, it is obvious asymmetric behavior (i.e. excessive shocks) as well as industry specific interaction are important dimensions to understanding international financial market linkages. In particular, the investigation into industry specific indexes by applying the MARS model allowed us to untangle the data and capture the asymmetric dynamics as well as sector specific unique characteristics in international financial markets. The sector specific MARS study results revealed the strong linkages when markets were excessively volatile and also identified the difference between the impact of positive and negative extreme price movements with great detail. Our research revealed the advantages of applying the MARS model to international financial markets.

The findings of our research can benefit international portfolio managers in many ways. First, our results should alert the managers to the existence of price comovements in international stock markets and help them be aware of the possible limitations of international diversification. Second, our results from the inter-sector study should cause the portfolio manager to consider diversifying international portfolios on a sector basis as well as by country. Third, through the utilization of the MARS model, a portfolio manager can receive very specific information on how to rebalance and/or hedge their portfolio after an extreme price movement in the market which traded just prior to its own open. Given the shake-up in international financial markets recently due to the subprime mortgage debacle, further research which incorporates the latest data and a volatility model should be a very interesting and fruitful undertaking.

\section{References}

Becker, Finnerty, \& Gupta (1990). The Intertemporal Relation Between the U.S. and Japanese Stock Markets, Journal of Finance, XLV (4), pp. 1297-1306. doi:10.2307/2328726, http://dx.doi.org/10.2307/2328726

Bialkowski, J., Bohl, M., \& Serwa, D. (2006). Testing for Financial Spillovers in Calm and Turbulent Periods, The Quarterly Review of Economics and Finance, 46, pp. 397-412. doi:10.1016/j.qref.2006.04.001, http://dx.doi.org/10.1016/j.qref.2006.04.001

Campbell, R., Koedijk, K., \& Kofman, P. (2002). Financial Contagion and International Portfolio Flows, Financial Analysts Journal, 58, pp.35-50. doi:10.2469/faj.v58.n1.2508, http://dx.doi.org/10.2469/faj.v58.n1.2508

Chan, K. C., Karolyi, G. A., \& Stultz, R. M. (1992). Global Financial Markets and the Risk Premium on U.S. Equity, Journal of Financial Economics, 32, pp. 137-168. doi:10.1016/0304-405X(92)90016-Q, http://dx.doi.org/10.1016/0304-405X(92)90016-Q 
Cheung, Y. W., He, J., \& Ng, L. (1997). Common Predictable Components in Regional Stock Markets, Journal of Business and Economic Statistics, 15, pp. 35-42. doi:10.2307/1392071, http://dx.doi.org/10.2307/1392071

Clarkson, P., Ragunathan, V., \& Nowland, J. (2002). The Relative Importance of Domestic and Global Factors in Explaining Australian Stock Returns, International Review of Finance, 3, pp. 1-25. doi:10.1111/1468-2443.00031, http://dx.doi.org/10.1111/1468-2443.00031

DeSantis, G. \& Gerard, B. (1997). International Asset Pricing and Portfolio Diversification with Time Varying Risk, Journal of Finance, 52, pp. 1881-1912. doi:10.2307/2329468, http://dx.doi.org/10.2307/2329468

Dungey, M. \& Martin, V. (2007). Unraveling Financial Market Linkages during Crises, Journal of Applied Econometrics, 22, pp. 89-119. doi:10.1002/jae.936

Ehrmann, M, Fratzscher, M., \& Roberto, R. (2005). Measuring International Financial Transmission, Working Paper, European Central Bank, 452, pp. 2-47.

Eun, C. S. \& Shim, S. (1989). International Transmission of Stock Market Movements, Journal of Financial and Quantitative Analysis, 24, pp. 241-256. doi:10.2307/2330774, http://dx.doi.org/10.2307/2330774

Evans, T. \& McMillan, D. G. (2009). Asymmetric Return Patterns: Evidence from 33 International Stock Market Indices, Applied Economics Letters, 16, pp. 775-779. doi:10.1080/13504850701222020, http://dx.doi.org/10.1080/13504850701222020

Friedman, J. H. (1991). Multivariate Adaptive Regression Splines (with discussion), Annals of Statistics, 19, 1. doi:10.1214/aos/1176347963, http://dx.doi.org/10.1214/aos/1176347963

Grubel, H. G. (1968). Internationally Diversified Portfolios: Welfare Gains and Capital Flows, American Economic Review, 58, pp. 1299-14.

Grubel, H. G. \& Fadner, D.K. (1971). The Interdependence of International Equity Markets, Journal of Finance, pp. 89-94. doi:10.2307/2325743, http://dx.doi.org/10.2307/2325743

Hilliard, Jimmy (1979) The Relationship Between Equity Indices on World Exchanges, Journal of Finance, pp. 103-114. doi:10.2307/2327147, http://dx.doi.org/10.2307/2327147

Ishii, Y. (2008). International Transmissions in US-Japanese Stock Markets, Applied Financial Economics, 18 (13-15), pp. 1193-1200. doi:10.1080/09603100701578981, http://dx.doi.org/10.1080/09603100701578981

Jaffe, J. \& Westerfield, R. (1985). Patterns in Japanese Common Stock Returns: Day of the Week and Turn of the Year Effects, Journal of Financial and Quantitative Analysis, 20, pp. 261-271. doi:10.2307/2330959, http://dx.doi.org/10.2307/2330959

Kim, H. W., Stern, L., \& Stern, M. (2009). Nonlinear Mean Reversion in the G7 Stock Markets, Applied Financial Economics, 19, pp. 347-355. doi:10.1080/09603100802389007, http://dx.doi.org/10.1080/09603100802389007

Lessard, D. R. (1974). World, National, and Industry Factors in Equity Returns, Journal of Finance, p. 379. doi:10.2307/2978807, http://dx.doi.org/10.2307/2978807

Lewis, P.A.W. \& Stevens, J. G. (1991) Nonlinear Modeling of Time Series Using Multivariate Adaptive Regression Splines (MARS), Journal of American Staistics Association,, 86, 864 $\neg 877$.

Lin, W. L., Engle, R. F., \& Ito, T. (1994). Do Bulls and Bears Move Across Borders? International Transmission of Stock Returns and Volatility as the World Turns, Review of Financial Studies, 7, pp. 507-537. doi:10.1093/rfs/7.3.507, http://dx.doi.org/10.1093/rfs/7.3.507

Odier, P, \& Solnik, B. (1993). Lessons for International Asset Allocation, Financial Analyst Journal, 49, pp. 63-77. doi:10.2469/faj.v49.n2.63, http://dx.doi.org/10.2469/faj.v49.n2.63

Panton, D. B., Lessig, V. P., \& Joy, O. M. (1976). Comovement of International Equity Markets: A Taxonomic Approach, Journal of Financial and Quantitative Analysis, pp. 415-432. doi:10.2307/2330417, http://dx.doi.org/10.2307/2330417

Solnik, B. H. (1974). Why Not Diversify Internationally, Financial Analysts Journal, 30, pp. 48-54. doi:10.2469/faj.v30.n4.48, http://dx.doi.org/10.2469/faj.v30.n4.48

Stokes, H. H. (2003). Specifying and Diagnostically Testing Econometric Models, 2nd Edition.

Stokes, H. H. (2009). Specifying and Diagnostically Testing Econometric Models, Unpublished manuscript for 3rd Edition.

Notes

Note 1. For the VAR model, variables were classified as significant if t-value $\geq 1.96$ (i.e. significant at the $5 \%$ significant level, $\alpha=0.05$ ). For some of the markets there is a brief overlap between the open of one country's market and the previous close of the other country. 
Note 2. Trading hours: Japan (1800-2:00 EST) $\rightarrow$ Paris (3:00-9:30 EST) \& London (4:00-10:30 EST) $\rightarrow$ New York \& Toronto (9:30-16:00).

Note 3. The MARS results report only significant variables.

Table 1. VAR Results for Broad-Based Indexes*

\begin{tabular}{|c|c|c|c|c|c|c|c|c|c|c|}
\hline \multirow{2}{*}{$\begin{array}{l}\text { Model } \\
\text { Variables }\end{array}$} & \multicolumn{2}{|c|}{$\begin{array}{l}\text { Japan } \\
\text { (NKY Index) }\end{array}$} & \multicolumn{2}{|c|}{$\begin{array}{l}\text { UK } \\
\text { (MIB30 Index) }\end{array}$} & \multirow{2}{*}{$\begin{array}{l}\text { France } \\
\text { Index) } \\
\text { Coeff } \\
\end{array}$} & \multirow{2}{*}{$\frac{(\mathrm{SBF} 250}{\mathrm{t} \text { stat }}$} & \multirow{2}{*}{$\begin{array}{l}\text { Canada } \\
\text { Index) }\end{array}$} & \multirow{2}{*}{$\begin{array}{l}\text { (TXEQ } \\
\mathrm{t} \text { stat } \\
\end{array}$} & \multicolumn{2}{|c|}{$\begin{array}{l}\text { U.S. } \\
\text { (SPX Index) }\end{array}$} \\
\hline & Coeff & $\mathrm{t}$ stat & Coeff & $\mathrm{t}$ stat & & & & & Coeff & $\mathrm{t}$ stat \\
\hline JP & -0.10 & -4.57 & 0.16 & 9.45 & 0.20 & 10.60 & 0.04 & 2.94 & 0.00 & -0.02 \\
\hline UK & 0.04 & 0.92 & -0.11 & -3.19 & -0.09 & -2.29 & 0.16 & 5.37 & 0.21 & 6.44 \\
\hline FR & 0.10 & 2.55 & -0.08 & -2.48 & -0.10 & -2.66 & 0.28 & 10.6 & 0.30 & 10.26 \\
\hline $\mathrm{CA}$ & 0.07 & 1.86 & -0.01 & -0.30 & 0.02 & 0.54 & 0.03 & 1.01 & 0.00 & 0.16 \\
\hline US & 0.34 & 9.50 & 0.32 & 11.06 & 0.35 & 10.83 & -0.11 & -4.37 & -0.22 & -8.03 \\
\hline
\end{tabular}

The tables shows markets in Asia (Japan) significantly influenced Europe (UK and France), Europe significantly influenced North America (U.S. and Canada), and North America significantly influenced Japan. Japan's stock market index daily returns $\left(\mathrm{NK}_{\mathrm{JP}, \mathrm{t}}\right)$ were significantly influenced by the U.S. market's performance ( $\left.\mathrm{SP}_{\mathrm{U} . \mathrm{S} . \mathrm{t}-1}\right)$

*: The summary table from $\operatorname{VAR}(2)$ model. Only first lag coefficients are included due to space limitation.

Shade areas: previous market.

Table 2. VAR Results for Industry-Specific Indexes*

\begin{tabular}{|c|c|c|c|c|c|c|c|c|c|c|}
\hline Model & Japan & & UK & & France & & Canada & & US & \\
\hline & Coeff & $\mathrm{t}$ stat & Coeff & t stat & Coeff & t stat & Coeff & $\mathrm{t}$ stat & Coeff & t stat \\
\hline \multicolumn{11}{|c|}{ A. Utility Index (UT) } \\
\hline Japan & -0.04 & -2.01 & 0.08 & 4.25 & 0.13 & 3.58 & 0.04 & 2.13 & 0.03 & 1.56 \\
\hline UK & 0.02 & 0.96 & -0.03 & -1.60 & -0.16 & -3.74 & 0.11 & 4.89 & 0.07 & 2.87 \\
\hline France & -0.02 & -1.86 & 0.00 & 0.15 & 0.02 & 1.13 & 0.02 & 2.27 & 0.06 & 4.68 \\
\hline Canada & 0.03 & 1.24 & 0.02 & 1.23 & 0.06 & 1.58 & -0.04 & -1.81 & -0.03 & -1.39 \\
\hline US & 0.04 & 2.09 & 0.10 & 5.69 & 0.25 & 6.91 & 0.00 & -0.16 & 0.04 & 2.06 \\
\hline
\end{tabular}

B. Technology Index (TE)

\begin{tabular}{l|ll|lllll|llll} 
Japan & 0.03 & 1.58 & 0.28 & 9.72 & 0.28 & 9.53 & 0.05 & 1.53 & 0.07 & 2.86 \\
UK & 0.05 & 3.11 & -0.02 & -0.93 & -0.05 & -1.91 & 0.24 & 8.58 & 0.12 & 6.17 \\
France & 0.09 & 5.70 & -0.03 & -1.23 & -0.05 & -1.76 & 0.38 & 13.74 & 0.25 & 13.43 \\
Canada & 0.02 & 1.46 & 0.03 & 1.72 & 0.05 & 2.63 & -0.02 & -1.08 & 0.00 & 0.31 \\
US & 0.29 & 14.93 & 0.20 & 6.78 & 0.27 & 8.62 & -0.13 & -3.61 & -0.20 & -8.52 \\
\hline
\end{tabular}

C. Health Index (HC)

\begin{tabular}{l|ccc|cccc|c|cccc} 
Japan & -0.09 & -4.71 & 0.14 & 5.89 & 0.12 & 4.58 & 0.06 & 1.90 & 0.03 & 1.45 \\
UK & 0.06 & 3.28 & -0.05 & -2.46 & 0.01 & 0.34 & 0.11 & 4.14 & 0.19 & 10.65 \\
France & 0.06 & 3.74 & -0.03 & -1.28 & -0.08 & -3.61 & 0.11 & 4.36 & 0.11 & 7.03 \\
Canada & 0.03 & 2.39 & -0.01 & -0.87 & -0.01 & -0.42 & 0.05 & 2.34 & -0.02 & -1.47 \\
US & 0.14 & 7.31 & 0.36 & 14.58 & 0.34 & 12.61 & 0.03 & 0.81 & -0.07 & -3.41 \\
\hline
\end{tabular}

D. Energy Index (EN)

\begin{tabular}{l|lll|lllllllll} 
Japan & -0.02 & -1.05 & 0.05 & 3.56 & 0.06 & 3.48 & 0.04 & 3.30 & 0.01 & 1.08 \\
UK & -0.03 & -0.97 & -0.16 & -6.29 & -0.07 & -2.46 & 0.23 & 11.68 & 0.32 & 15.90 \\
France & 0.08 & 2.83 & 0.02 & 0.81 & -0.07 & -3.13 & 0.11 & 6.07 & 0.14 & 7.64 \\
Canada & 0.15 & 4.37 & 0.09 & 3.28 & 0.16 & 5.45 & -0.03 & -1.38 & 0.01 & 0.43 \\
US & 0.11 & 3.26 & 0.33 & 12.25 & 0.28 & 9.30 & -0.01 & -0.58 & -0.20 & -8.71 \\
\hline
\end{tabular}

The table shows strong integration of international market in sector based indexes. In the utilities sector, one's own lagged daily returns significantly influenced its own market with the exception of France and UK. The results for the technology industry displayed only the U.S. as the sole country where its own lagged performance significantly impacted its market. As for heath care, all the countries showed its own previous price movement significantly influenced the following trading period. In energies, with the exception of Japan and Canada, all other countries showed one's lagged price effect significantly impacted its own price movement.

*: The summary table from VAR(2) model. Only first lag coefficients are included due to space limitation.

Shade areas: previous market. 
Table 3. Asymmetric Threshold Marginal Effects by Country on Broad and Industry Specific Indexes

\begin{tabular}{|c|c|c|c|c|c|c|c|c|c|}
\hline \multicolumn{2}{|c|}{ Japan } & \multicolumn{2}{|c|}{ UK } & \multicolumn{2}{|c|}{ France } & \multicolumn{2}{|c|}{ Canada } & \multicolumn{2}{|c|}{ US } \\
\hline Threshold & $\begin{array}{c}\text { Marginal } \\
\text { Effects }\end{array}$ & Threshold & $\begin{array}{c}\text { Marginal } \\
\text { Effects }\end{array}$ & Threshold & $\begin{array}{c}\text { Marginal } \\
\text { Effects }\end{array}$ & Threshold & $\begin{array}{c}\text { Marginal } \\
\text { Effects }\end{array}$ & Threshold & $\begin{array}{c}\text { Marginal } \\
\text { Effects }\end{array}$ \\
\hline & & & \multicolumn{2}{|c|}{ BROAD INDEX } & & & & & \\
\hline$U_{t-1}>-0.27$ & 0.29 & $U_{\mathrm{t}-1}>-1.95$ & 0.20 & $\mathrm{US}_{\mathrm{t}-1}>-1.87$ & 0.25 & $U S_{t-1}>-1.84$ & 0.00 & $\mathrm{FR}_{\mathrm{t}}>-1.51$ & 0.45 \\
\hline$U_{\mathrm{t}-1}<-0.27$ & 0.54 & $\mathrm{US}_{\mathrm{t}-1}<-1.95$ & 0.49 & $\mathrm{US}_{\mathrm{t}-1}<-1.87$ & 0.43 & $U_{\mathrm{t}-1}<-1.87$ & 0.55 & $\mathrm{FR}_{\mathrm{t}}<-1.51$ & 0.42 \\
\hline $\mathrm{FR}_{\mathrm{t}-1}<-2.80$ & 0.14 & $J A_{t}>-0.04$ & 0.10 & $J A_{t}>-0.03$ & 0.13 & $F R_{t}>2.73$ & 0.00 & & \\
\hline $\mathrm{FR}_{\mathrm{t}-1}>-2.80$ & -0.48 & $J A_{t}<-0.04$ & 0.19 & $J A_{t}<-0.03$ & 0.24 & $\mathrm{FR}_{\mathrm{t}}<2.73$ & 0.42 & & \\
\hline & & & \multicolumn{2}{|c|}{ UTILITY INDEX } & & & & & \\
\hline$U K_{t-1}>3.18$ & -0.68 & $\mathrm{US}_{\mathrm{t}-1}>-1.44$ & 0.00 & $U S_{t-1}>3.07$ & 0.94 & $\mathrm{UK}_{\mathrm{t}}>0.54$ & 0.00 & $U K_{t}>-1.67$ & 0.10 \\
\hline \multirow[t]{4}{*}{$\mathrm{UK}_{\mathrm{t}-1}<3.18$} & 0.00 & $\mathrm{US}_{\mathrm{t}-1}<-1.44$ & 0.39 & US $_{\mathrm{t}-1}<3.07$ & 0.20 & $\mathrm{UK}_{\mathrm{t}}<0.54$ & 0.17 & $\mathrm{UK}_{\mathrm{t}}<-1.67$ & 0.00 \\
\hline & & & & $\mathrm{JA}_{\mathrm{t}}>1.56$ & 0.00 & & & $F R_{t}>-6.43$ & 0.07 \\
\hline & & & & $\mathrm{JA}_{\mathrm{t}}<1.56$ & 0.18 & & & $F R_{t}<-6.43$ & -0.21 \\
\hline & & & \multicolumn{2}{|c|}{ TECHNOLOGYINDEX } & & & & & \\
\hline $\mathrm{US}_{\mathrm{t}-1}>5.29$ & -0.32 & $\mathrm{US}_{\mathrm{t}-1}>1.27$ & 0.00 & $\mathrm{US}_{\mathrm{t}-1}>-4.29$ & 0.30 & $U_{\mathrm{t}-1}>-1.92$ & 0.00 & $\mathrm{UK}_{\mathrm{t}}>7.25$ & 0.41 \\
\hline $\mathrm{US}_{\mathrm{t}-1}<5.29$ & 0.00 & $\mathrm{US}_{\mathrm{t}-1}<1.27$ & 0.30 & $\mathrm{US}_{\mathrm{t}-1}<-4.29$ & 0.00 & $\mathrm{US}_{\mathrm{t}-1}<-1.92$ & 0.51 & $\mathrm{UK}_{\mathrm{t}}<7.25$ & 0.12 \\
\hline $\mathrm{UK}_{\mathrm{t}-1}>5.76$ & 0.27 & $\mathrm{JA}_{\mathrm{t}}>-1.60$ & 0.26 & $J A_{t}>5.11$ & 0.00 & $\mathrm{UK}_{\mathrm{t}}>7.25$ & 0.75 & $\mathrm{FR}_{\mathrm{t}}>-5.25$ & 0.27 \\
\hline $\mathrm{UK}_{\mathrm{t}-1}<5.76$ & 0.04 & $J A_{t}<-1.60$ & 0.34 & $J A_{t}<5.11$ & 0.27 & $\mathrm{UK}_{\mathrm{t}}<7.25$ & 0.23 & $\mathrm{FR}_{\mathrm{t}}<-5.25$ & 0.46 \\
\hline $\mathrm{FR}_{\mathrm{t}-1}>7.45$ & -0.27 & & & & & $\mathrm{FR}_{\mathrm{t}}>-0.31$ & 0.29 & & \\
\hline \multirow[t]{2}{*}{$\mathrm{FR}_{\mathrm{t}-1}<7.45$} & 0.11 & & & & & $F R_{t}<-0.31$ & 0.46 & & \\
\hline & & & \multicolumn{2}{|c|}{ HEALTH INDEX } & & & & & \\
\hline$U_{\mathrm{t}-1}>-1.61$ & 0.12 & $U_{t-1}>-2.30$ & 0.29 & $U S_{t-1}>-1.37$ & 0.29 & $F R_{t}>2.13$ & 0.00 & $\mathrm{FR}_{\mathrm{t}}>1.19$ & 0.13 \\
\hline \multirow[t]{4}{*}{$\mathrm{US}_{\mathrm{t}-1}<-1.61$} & 0.32 & $\mathrm{US}_{\mathrm{t}-1}<-2.30$ & 0.81 & $U_{\mathrm{t}-1}<-1.37$ & 0.51 & $\mathrm{FR}_{\mathrm{t}}<2.13$ & 0.14 & $\mathrm{FR}_{\mathrm{t}}<1.19$ & 0.10 \\
\hline & & & & $J A_{t}>-0.20$ & 0.19 & $\mathrm{UK}_{\mathrm{t}}>-2.34$ & 0.89 & $\mathrm{UK}_{\mathrm{t}}>4.78$ & 0.00 \\
\hline & & & & $J A_{t}<-0.20$ & 0.00 & $\mathrm{UK}_{\mathrm{t}}<-2.34$ & 0.34 & $\mathrm{UK}_{\mathrm{t}}<4.78$ & 0.19 \\
\hline & & & \multicolumn{2}{|c|}{ ENERGY INDEX } & & & & & \\
\hline $\mathrm{CA}_{\mathrm{t}-1}>3.84$ & -1.00 & $\mathrm{US}_{\mathrm{t}-1}>3.81$ & 1.42 & $U_{\mathrm{t}-1}>3.46$ & 0.74 & $\mathrm{UK}_{\mathrm{t}}>4.08$ & 0.00 & $\mathrm{UK}_{\mathrm{t}}>4.70$ & 0.00 \\
\hline $\mathrm{CA}_{\mathrm{t}-1}<3.84$ & -0.22 & $\mathrm{US}_{\mathrm{t}-1}<3.81$ & 0.31 & $\mathrm{US}_{\mathrm{t}-1}<3.46$ & 0.25 & $\mathrm{UK}_{\mathrm{t}}<4.08$ & 0.26 & $\mathrm{UK}_{\mathrm{t}}<4.70$ & 0.33 \\
\hline $\mathrm{FR}_{\mathrm{t}-1}>4.90$ & 0.76 & $C A_{t-1}>0.01$ & 0.00 & $C A_{t-1}>-0.99$ & 0.10 & & & $F R_{t}>-5.10$ & 0.12 \\
\hline $\mathrm{FR}_{\mathrm{t}-1}<4.90$ & 0.07 & $\mathrm{CA}_{\mathrm{t}-1}<0.01$ & 0.16 & $C A_{t-1}<-0.99$ & 0.31 & & & $\mathrm{FR}_{\mathrm{t}}<-5.10$ & 1.06 \\
\hline
\end{tabular}

We summaries this tables from MARS results. To save space, own lag effects were excluded and only variables where the effects were larger than 0.1 were included. A marginal effect display of 0.00 means no effect and not included in MARS results, but included in this table for comparison purpose. For a test on the hypothesis of the threshold coefficients the following t statistic was applied (all threshold coefficients were confirmed as significant at $1 \%$ significance level):

$$
t=\frac{\left(\hat{\beta}_{1}-\hat{\beta}_{2}\right)}{\sqrt{\left(\frac{\left(n_{1}-k_{1}\right) \hat{\sigma}_{1}^{2}+\left(n_{2}-k_{2}\right) \hat{\sigma}_{2}^{2}}{\left(n_{1}-k_{1}\right)\left(n_{2}-k_{2}\right)}\right)\left(\frac{1}{n_{1}}+\frac{1}{n_{2}}\right)}} \text {, where }
$$

$\hat{\beta}_{1}$ and $\hat{\beta}_{2}$ are estimated coefficients of threshold, $\left(n_{i}-k_{i}\right)$ and $\hat{\sigma}_{i}^{2}$ are degrees of freedom and sample variances of estimated coefficients, respectfully. 


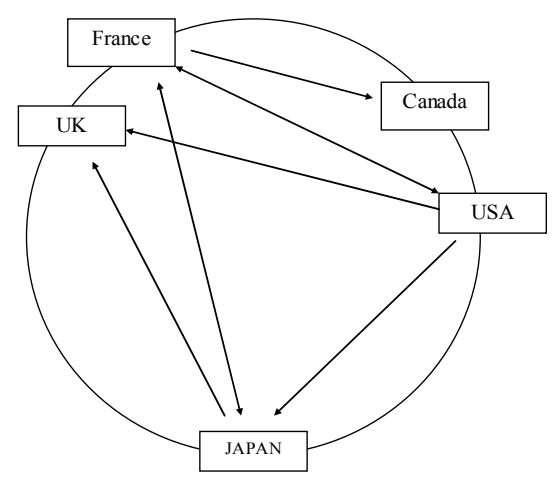

Figure 1. Direction of Markets in Broad-Based Indexes

The broad-based industry index displayed similar results as our VAR study. Although there appears to be some interaction between France and Japan's market, the overall flow theme is fairly consistent with the VAR results - the previous closing markets influence the following market's trading session. Asia $\rightarrow$ Europe $\rightarrow \mathrm{N}$. America.

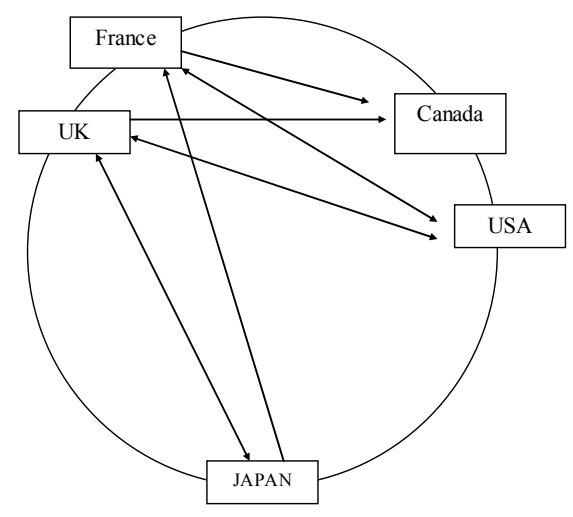

A. Utility Index

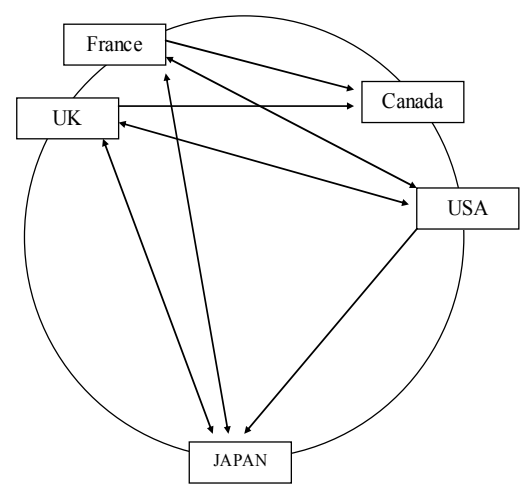

C. Health Care Index

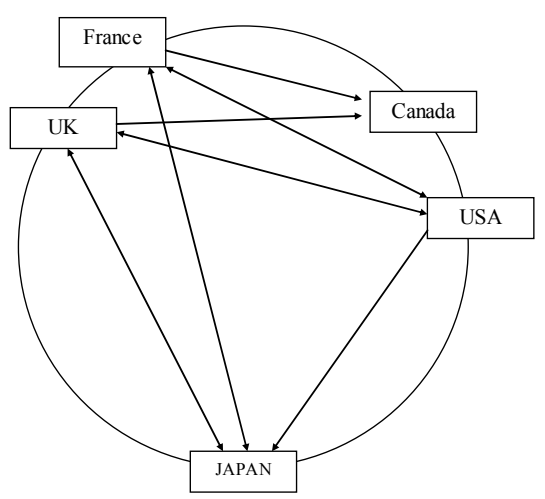

B. Technology Index

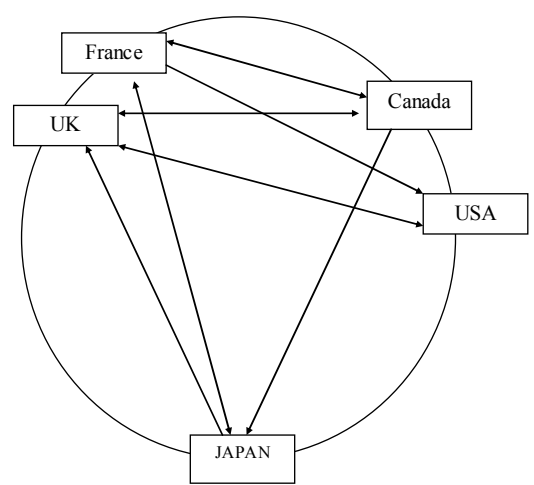

D. Energy Index

Figure 2. Direction of Markets in Industry-Specific Indexes

The sector specific results for MARS were also very similar with the VAR study, with the exception of Japan. Just as the VAR results showed for the Canadian market, the MARS model also displayed the technology sector being most influenced by other countries while healthcare was significantly influenced by domestic factors. 


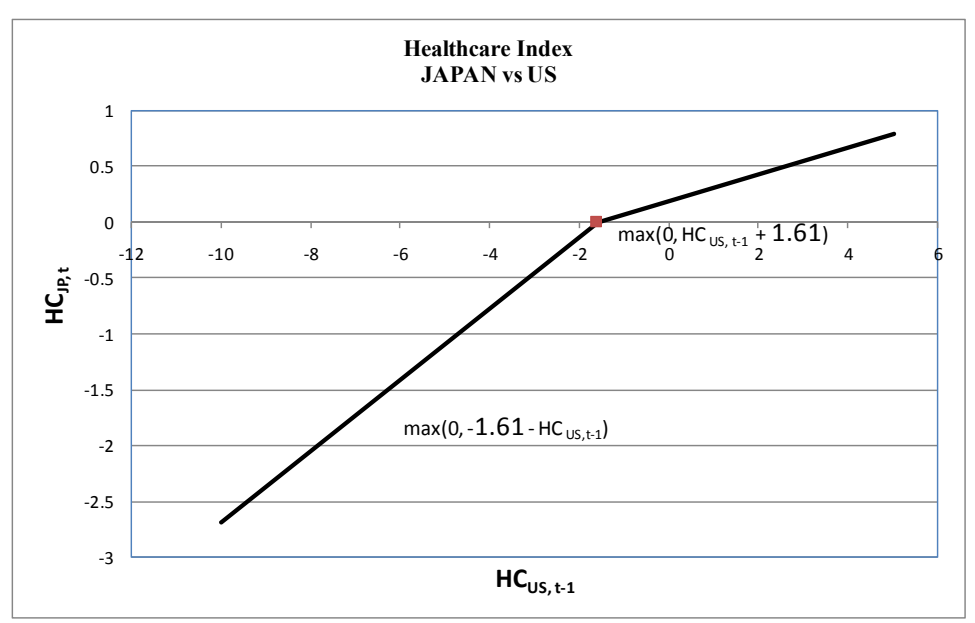

Figure 3. Asymmetric Effects of U.S. Health Care on Japan Health Care index

The MARS model showed $\mathrm{HC}_{\mathrm{US}, \mathrm{t}+1}$ (daily rate of return of the U.S. healthcare stock index) influences $\mathrm{HC}_{\mathrm{JP}, \mathrm{t}}$ (daily rate of return of Japan's healthcare stock index) by $-0.32 *\left(-1.61\right.$ minus $\left.\mathrm{HC}_{\mathrm{US}, t+1}\right)$ when $\mathrm{HC}_{\mathrm{US}, \mathrm{t}+1}$ is less than -1.61 (199 times) and $0.12 *\left(\mathrm{HC}_{\mathrm{US}, \mathrm{t}+1}+1.61\right)$ when $\mathrm{HC}_{\mathrm{US}, \mathrm{t}+1}$ is greater than -1.61 (2479 times).

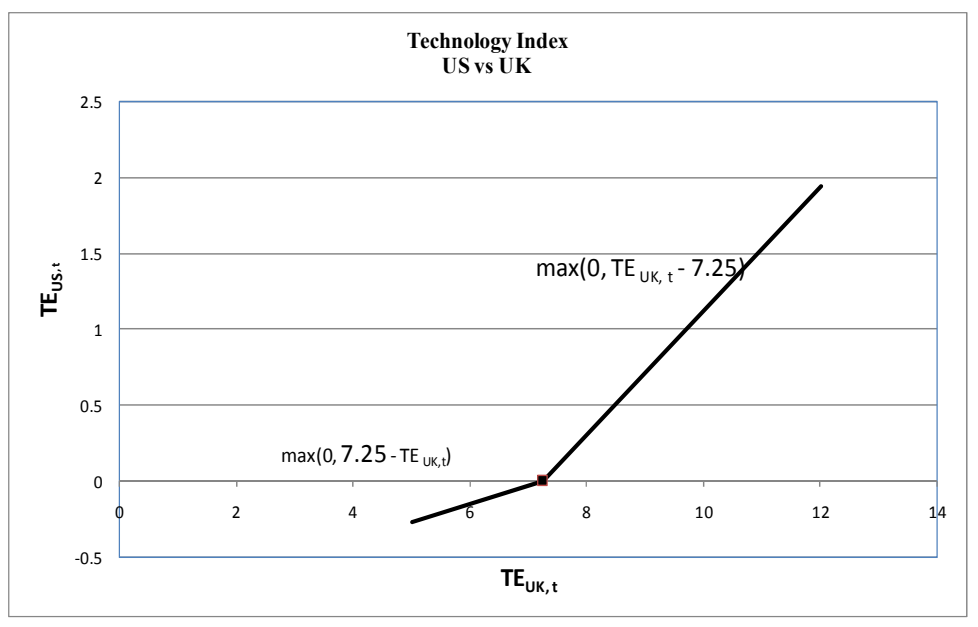

Figure 4. Asymmetric Effects of UK Technology on U.S. Technology Index

The MARS model showed $\mathrm{TE}_{\mathrm{UK}, \mathrm{t}}$ is expected to influence $\mathrm{TE}_{\mathrm{US}, \mathrm{t}}$ by $0.41 *\left(\mathrm{TE}_{\mathrm{UK}, \mathrm{t}}\right.$ minus 7.25$)$ when $\mathrm{TE}_{\mathrm{UK}, \mathrm{t}}$ is greater than $7.25(24$ times) and $0.12 *\left(7.25-\mathrm{TE}_{\mathrm{UK}, \mathrm{t}}\right)$ when $\mathrm{TE}_{\mathrm{UK}, \mathrm{t}}$ is less than 7.25 (2669 times). 